\title{
Ciência, fronteiras e nação: comissões brasileiras na demarcação dos limites territoriais entre Brasil e Bolívia, 1895-1901
}

Science, frontiers and nation: Brazilian committees in demarcation of territorial boundaries between Brazil and Bolivia, 1895-1901

Moema de Rezende Vergara

Resumo: $\bigcirc$ artigo trata de três expedições brasileiras à Amazônia Ocidental que tiveram por missão demarcar os limites entre Brasil e Bolívia nos anos 1895-1901. O objetivo é apreender o papel que a ciência desempenhou em uma negociação que contribuiu para que o Brasil tivesse as feições territoriais da atualidade. $\bigcirc$ artigo procura abordar, sob o ponto de vista da história da ciência, um tema tradicionalmente estudado pelo viés da geopolítica, ou seja, a formação das fronteiras internacionais, evidenciando uma intercessão entre institucionalização da ciência e formação da nação.

Palavras-chave: Expedição científica. Território. História da astronomia. Acre. Brasil. Bolívia.

Abstract: The article analyzes three Brazilian expeditions to Western Amazon whose mission was to demarcate the boundary between Brazil and Bolivia during the years 1895-1901. The goal is to seize the role of science in a negotiation that gave to Brazil its actual territorial shape. In the point of view of history of science, the paper deals with a traditional topic of geopolitics - the formation of international borders - highlighting the intersection between institutionalization of science and the construction of nation.

Keywords: Scientific expedition. Territory. History of Astronomy. Acre. Brazil. Bolivia.

Museu de Astronomia e Ciências Afins/MCT. Rio de Janeiro, Rio de Janeiro, Brasil (moema@mast.br).

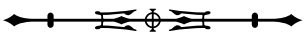




\section{INTRODUÇÃO}

O presente artigo trata de três expedições à Amazônia Ocidental que tiveram por missão demarcar o limite entre Brasil e Bolívia durante a Primeira República brasileira, em um período anterior à 'era Barão do Rio Branco'. Estas comissões foram chefiadas, respectivamente, por Gregório Thaumaturgo de Azevedo (1895), Augusto Cunha Gomes (1897) e Luiz Cruls (1901). A última é referida na historiografia da ciência como sendo a que contribuiu para o famoso Tratado de Petrópolis. Entretanto, a solução para o problema se deu puramente no plano político, sem levar em consideração os trabalhos técnicos então realizados, o que invalida a relação de causalidade entre a expedição chefiada por Cruls e o fim do litígio com a Bolívia, como se verá no decorrer do texto.

A trama da história dos limites setentrionais brasileiros com a Bolívia é de grande complexidade e é objeto de interesse de especialistas em diferentes disciplinas. $\bigcirc$ desafio que ora se apresenta é apreender qual o papel que a ciência desempenhou neste jogo, que contribuiu para que o Brasil tivesse as feições territoriais da atualidade. Este artigo pode ser considerado como um exercício, no qual se toma por tema um assunto tradicionalmente estudado pelo viés da geopolítica, isto é, a formação das fronteiras internacionais, para também entender a intercessão entre ciência e nação.

$O$ leitor deve ter em mente que no momento em que estão se desenrolando estes acontecimentos, o Brasil ainda não possuía um mapa de seu território, segundo os padrões internacionais de cientificidade cartográfica, o que só ocorrerá mais tarde. $\bigcirc$ primeiro mapa do Brasil que obedeceu a tais critérios, ou seja, que foi elaborado na escala ao milionésimo, foi feito pelo Clube de Engenharia para a Exposição Comemorativa do Centenário da Independência, em 1922.

O episódio da delimitação das fronteiras com a Bolívia é uma fração de um conjunto mais amplo.
Alguns dos obstáculos que constam nos relatos das referidas expedições, como o ataque de índios bravios, o território desconhecido e de difícil acesso, eram as mesmas razões atribuídas para a falta da carta nacional (Beaurepaire Rohan, 1878). Para a elaboração de tal mapa, ter as fronteiras demarcadas era condição fundamental ${ }^{1}$, mas não o único fator preponderante. Neste sentido, é importante se ter em mente que a delimitação de fronteiras e o mapeamento são processos que se entrecruzam, mas não são sinônimos. Importante lembrar que os mapas conferem o contorno da nação, espaço de exercício da soberania do Estado; é dentro desses limites que se desenvolvem os processos e rituais de constituição da nacionalidade (Moraes, 2005).

$O$ traçado da linha de fronteira não obedece, necessariamente, aos imperativos da natureza, segundo as palavras de Wilford (2000, p. 205): "essas linhas colocam dentro da geometria as expectativas, o destino político, a garantia de soberania. E falam em seus traçados de batalhas passadas, barganhas, compromissos diplomáticos".

No início da república brasileira, o Tratado que ainda estava em vigor procedia do Império e estipulava que a região do atual estado do Acre pertencia à Bolívia, e assim era reconhecida pela chancelaria brasileira da época (Brasil, 1939). Contudo, o governo brasileiro instituiu três comissões sucessivas que tiveram por objetivo traçar o limite na região amazônica e verificar a localização da principal nascente do rio Javari, cujo desconhecimento gerava controvérsias na interpretação daquele Tratado. O labor destas comissões quase nunca é mencionado nos anais da história da ciência no Brasil. Geradas em circunstâncias de enorme agitação política, tem-se a impressão de que seus trabalhos evaporam no calor das discussões. O objetivo deste texto é fazer uma 'anatomia' das comissões demarcadoras, ou seja, por meio de um corte horizontal, identificar o

Cabe estabelecer uma distinção entre 'limite' e 'fronteira'. Este último termo é mais abrangente por compreender não só uma linha, mas uma região ou faixa territorial. Já o termo 'limite' remete a uma concepção muito mais precisa, linear e perfeitamente definida no terreno (Krukoski, 2009).

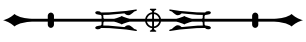


que possuíam em comum e como eram realizados os trabalhos técnicos de seus membros.

\section{ANTECEDENTES HISTÓRICOS}

Os antecedentes do estabelecimento da fronteira na Amazônia Ocidental podem ser considerados como um evento de longa duração na história do Brasil, pois remontam ao período colonial. Nas palavras de Thaumaturgo de Azevedo, a questão de limites entre o Brasil e a Bolívia era secular. A primeira iniciativa de demarcação entre os dois países, posterior ao processo de independência, data de 1834, quando aquela República enviou um representante ao Rio de Janeiro negociar um tratado. O projeto boliviano partia de algumas premissas do Tratado de Santo Ildefonso, assinado entre Espanha e Portugal em 1777, com algumas retificações. O governo imperial não as aceitou, defendendo o anterior, de 1750, o Tratado de Madri (Azevedo, 1902).

A necessidade de determinação das nascentes do rio Javari pode ser vista como um elemento de continuidade entre vários períodos históricos. O Javari é mencionado nos tratados de Madri e de Santo Ildefonso, que estabeleceram a linha divisória entre os domínios espanhóis e portugueses na Amazônia. A fórmula se repete em ambos os tratados da seguinte forma:

(...) baixará a fronteira pelas águas dos rios Guaporé e Madeira até a paragem situada em igual distância do rio Maranhão ou Amazonas e da boca do Mamoré, e desde aquela aparagem continuará por uma linha leste-oeste até encontrar a margem oriental do rio Javari, que entra no Maranhão pela margem austral; e, baixando pelo álveo do mesmo Javari até onde desemboca no Amazonas, prosseguirá a águas abaixo deste rio, a que os espanhóis costumam chamar Orelllana e os índios Guiena, até a boca mais ocidental do Japurá, que deságua nele pela margem norte (apud Moreira, 1913, p. 137, grifo nosso). pouco explorado, este rio representava o marco "natural" e a derradeira presença portuguesa na Amazônia ocidental, sendo este fato também reconhecido pela Coroa espanhola. Peixoto (2002, p. 141) afirma que, se o Madeira era inegavelmente português e povoado, o Javari, devido à dificuldade de acesso, era um marco simbólico dos limites portugueses e posteriormente brasileiros com os países vizinhos. Assim, é possível inferir que, se o Madeira tornou-se brasileiro por sua ocupação secular, consolidada por meio do princípio uti possidetis, o Javari era um marco oferecido pela ideia de limite natural, ambos os rios podendo ser vistos como as balizas da política externa brasileira no Império, ou seja, ora se valendo da ideia de ocupação, ora de limite natural herdado do período colonial.

Durante o Império, o rio Javari, apesar da imprecisão da localização de suas nascentes, foi referido no Tratado de Amizade, Limites, Navegação e Comércio, de 1867, também conhecido por Tratado de Ayacucho, entre o Brasil e a Bolívia, como um marco para o estabelecimento da fronteira:

\begin{abstract}
Deste rio [o Madeira] para oeste, seguirá a fronteira por uma paralela, tirada da sua margem esquerda na latitude sul de $10^{\circ} 20^{\prime}$ a encontrar o rio Javari. Se o Javari tiver as suas nascentes ao norte daquela linha leste-oeste, seguirá a fronteira desde a mesma latitude por uma reta a buscar a origem principal do dito Javari (Moreira, 1913, p. 140, grifo nosso).
\end{abstract}

Em outras palavras, o Tratado de 1867 foi uma tentativa de garantir o território brasileiro em um espaço desconhecido. A conjuntura da assinatura daquele Tratado não era nada tranquila. Goes Filho (1999) lembra que o Tratado foi assinado durante a Guerra do Paraguai e que o Brasil precisava angariar mais simpatia na América Latina (além disso, havia receio de uma aliança entre Bolívia e Paraguai):
Peixoto (2002) assinala que o rio Javari seria o limite mais ocidental da fronteira portuguesa, o qual somente se alcançava após a jornada de oitenta e sete dias de canoa a partir de Belém do Pará. Segundo o autor, apesar de
Por isso havia pressa em resolver suas incertezas fronteiriças com a Bolívia, país com o qual tem a mais longa divisão comum; não podia esperar outro momento para negociar acordo possivelmente mais favorável (Goes Filho, 1999, p. 226). 
Os trabalhos de demarcação só se iniciam em 1870, com o fim da guerra. No Império, houve sete conferências ${ }^{2}$ entre os governos até a conclusão dos trabalhos da porção meridional da fronteira, em 1878, feita pelo governo brasileiro e ratificada pelo boliviano. A fronteira amazônica, contudo, continuava indefinida.

\section{CIÊNCIA E NAÇÃO, MAS QUE CIÊNCIA?}

Atualmente, quem olhar para as fronteiras brasileiras verá que grande parte delas obedece aos limites naturais, tais como rios, montanhas, entre outros acidentes geográficos. Somente 10\% delas foram traçadas a partir de medições geodésicas e astronômicas (Backheuser, 1944, p. 251). A geodésia possibilita a determinação de um ponto na superfície terrestre por meio da observação da esfera celeste $^{3}$. Nesse sentido, o sistema de coordenadas de latitude e longitude faz com que a cartografia se valha da aplicação do conhecimento astronômico para a localização terrestre. Nos séculos XVIII e XIX, houve um avanço na confecção de mapas, principalmente pelo desenvolvimento de instrumentos científicos, tais como o teodolito e o cronômetro, que possibilitaram a observação em variadas condições, como no mar e em lugares inexplorados (Sobel, 2008). A marcação através de uma linha geodésica é um trabalho de delimitação geralmente empregado em terrenos pouco explorados. Uma vez que este era o caso da parte ocidental da Amazônia, desde os tratados do século XVIII entre Portugal e Espanha já estava estabelecido que a demarcação seria feita através de uma linha geodésica.

A partir do século XIX, etapas dos trabalhos de demarcação contemplavam tanto o aspecto técnico quanto o histórico. Os precedentes históricos e as eventuais tentativas anteriores para o estabelecimento da fronteira são levados em consideração como ponto de partida, daí a importância dos mapas históricos e da análise de antigos documentos na chancelaria. Em seguida, há a etapa de 'delimitação', na qual se estabelece o acordo diplomático que versa sobre o assunto. Nesta ocasião, os negociadores dos países envolvidos decidem, à luz da documentação disponível, como deve ser traçada a linha delimitadora dos territórios que estão sendo definidos. Após essa fase essencialmente política, passa-se à 'demarcação', quando as comissões demarcadoras procuram interpretar no terreno as intenções dos diplomatas em seus gabinetes. Trata-se de uma fase técnica, que, no entanto, pode oferecer dificuldades de interpretação para encontrar no terreno o rio, a montanha ou outro acidente geográfico que tenha servido de base para a delimitação (Krukoski, 2009).

As comissões de demarcação da Primeira República elaboraram valiosos relatos de como a astronomia foi utilizada na cartografia brasileira, em um período anterior à aerofotometria e ao rastreamento por satélites, técnicas posteriores de mapeamento. Como afirmado anteriormente, os serviços de demarcação e de mapeamento não são equivalentes, apesar do trabalho de campo em ambos os casos possuir vários elementos em comum, como a utilização dos mesmos conhecimentos e instrumentos científicos, mesmo que seja para atingir finalidades distintas: a demarcação é o traçado de uma linha divisória entre dois países e o mapeamento é a construção de uma representação plana que agrega uma ampla gama de informações.

2 Lendo as atas destas conferências, vemos que o meridiano zero tomado como longitude de referência era o do Observatório do Rio de Janeiro. Cabe lembrar que, nas atas do período republicano, o meridiano utilizado é o de Greenwich. Este meridiano foi considerado a longitude zero a partir de 1884, durante o Congresso Internacional do Meridiano Zero, em Washington. O objetivo deste congresso foi estabelecer um padrão universal para os cálculos de longitude. Segundo Wilford (2000, p. 258), antes deste congresso, havia 14 meridianos diferentes utilizados na confecção de mapas. Interessante notar que o representante brasileiro foi Luiz Cruls, chefe da comissão de 1901.

3 Para Sobel (2008, p. 11), "as linhas que representam a latitude, os paralelos, de fato ficam paralelas umas às outras, envolvendo o globo do Equador aos pólos, numa série decrescente de anéis concêntricos. Os meridianos de longitude se posicionam de forma inversa: eles enlaçam o globo do Pólo Norte ao Pólo Sul, formando grandes círculos de tamanhos idênticos, todos convergindo para os mesmos pontos nas extremidades da Terra".

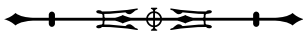


Segundo Lima (1999), uma das características das expedições científicas da Primeira República seria a valorização do sertão, aqui entendido como um espaço desconhecido em oposição ao litoral. A autora cita uma série de expedições que tinham uma dupla missão, ou seja, além de atender seus objetivos principais, como realizar obras de infraestrutura, de saneamento, de exploração, também deveriam conhecer o interior do país (Lima, 1999, p. 65-66). Assim, estas comissões demarcadoras se filiam a este perfil, pois, sem dúvida alguma, em seus relatórios pode-se ver tanto o esforço de executar a missão de demarcação quanto o de trazer aspectos regionais desconhecidos para o público do litoral.

Geralmente, as comissões de demarcação possuíam o seguinte formato: por se tratar de fronteiras internacionais, eram formadas pelo Ministério do Exterior e chefiadas por militares ou técnicos com conhecimento de geodésia, como engenheiros ou astrônomos; além dos instrumentos científicos e mantimentos, era levado um contingente de 40 a 50 praças, médicos ou farmacêuticos, oficiais e engenheiros civis. No caso da região amazônica, todo o pessoal e material era transportado em barcos e canoas ${ }^{4}$.

Ainda segundo Lima (1999, p. 62), o conhecimento produzido no âmbito destas viagens foi essencial para a formação de um imaginário social sobre aquela parte da realidade brasileira. Um dos caminhos pelos quais este conhecimento se incorporou ao imaginário nacional foi a circulação dos relatórios ministeriais, cujos conteúdos eram frequentemente publicados na imprensa. Figueirôa (2008), ao descrever os trabalhos da Comissão Geográfica e Geológica de São Paulo, estabelece características gerais de relatórios que podem ser vistas nos demais: após um comentário geral do chefe da expedição, seguiam-se diferentes textos técnicos "sobre geografia, geologia, botânica, meteorologia, coordenadas geográficas, população, presença de índios etc. Os escritos impressos são intercalados com páginas de fotografia e, ao final, encontram-se as cartas e mapas elaborados" (Figueirôa, 2008, p. 770).

A autora chama também a atenção para a construção de um discurso textual poderoso que utiliza o recurso das fotografias não só para ilustrar, mas para promover a construção de um outro discurso, visual, muitas vezes extrapolando as páginas dos relatórios. Como, por exemplo, no caso do rio Javari, cujas fotografias provenientes do relatório de Cunha Gomes foram fundamentais para guiar a comissão de Cruls. Este publicou as mesmas fotos em seu artigo na revista literária "Renascença", editada por Rodrigo Otávio e Henrique Bernardelli, em 1904. Nesse sentido, observa-se que as fotografias, além de desempenharem um importante papel na narrativa do relatório, também foram utilizadas para que o público em geral conhecesse a região, fornecendo subsídios para a construção de uma ideia sobre ela.

Voltando às viagens de demarcação, foi em 1895 que se reabriram as negociações diplomáticas com a Bolívia, com o protocolo para demarcação do MadeiraJavari, em função de novas necessidades geradas pela riqueza do ciclo da borracha. Segundo Tocantins (2009, p. 163-164), a exploração da borracha na Amazônia data desde as primeiras décadas do século XIX, tendo um crescimento acentuado a partir dos anos de 1860, acompanhando o processo global de industrialização e os avanços no campo da química, com a vulcanização e a utilização da borracha em diversos setores. Nos anos de 1880, a borracha já representava boa parte da receita brasileira, repercutindo no crescimento urbano de cidades como Belém do Pará e Manaus.

Até a assinatura do Tratado de Petrópolis, de 1903, quando se encerrou a chamada 'questão do Acre', foram realizadas oito conferências entre as comissões mistas

4 Concluída a missão, estas comissões se desfaziam. Atualmente, no Ministério das Relações Exteriores há duas comissões permanentes para tratar dos assuntos técnicos das fronteiras brasileiras: a Primeira Comissão Demarcadora de Limites, que fica em Belém do Pará, e a Segunda Comissão Demarcadora de Limites, no Rio de Janeiro. 
de limites do Brasil e da Bolívia ${ }^{5}$. A necessidade de se fazer novas viagens de exploração ao Javari fundava-se na suspeita de que o cálculo da nascente feito pelo Barão de Tefé, em 1874, que serviu para fixar o limite com o Peru, não estaria correto. E era com base nos resultados desta expedição que se estava estabelecendo as fronteiras entre o Brasil e a Bolívia, tendo em vista que o rio Javari percorre os três países. A intenção do Ministério das Relações Exteriores, naquele momento, era aproveitar um trabalho feito anteriormente para que se resolvesse o mais rápido possível e com baixos custos o litígio com a Bolívia. Tendo em vista o questionamento dos cálculos sobre a nascente do Javari e a conclusão da negociação dos limites com o Peru, durante todo o processo de discussão sobre as fronteiras entre o Brasil e a Bolívia o governo peruano ficou vigilante, temendo a perda de território. Não obstante, após o Tratado de 1903, foi aberta novamente a questão com o Peru e se instaurou a Comissão Mista BrasileiroPeruana de Reconhecimento do Alto Purus, chefiada por Euclides da Cunha entre os anos de 1904-1906.

\section{GREGÓRIO THAUMATURGO DE AZEVEDO}

$O$ protocolo de 10 de maio de $1895^{6}$, feito pelo então ministro das Relações Exteriores do Brasil, Carlos de Carvalho, e por Federico de Medina, ministro Plenipotenciário da Bolívia, instruía a comissão mista a traçar uma linha geodésica entre os rios Madeira e Javari, passando pelo rio Acre e avançando preferencialmente por terra. $\bigcirc$ texto explicitava claramente que não havia necessidade de verificar a posição da nascente principal do Javari porque os governos do Brasil e da Bolívia adotariam os mesmos cálculos utilizados na demarcação dos limites entre o Brasil e o Peru. Nesse sentido, a nascente do
Javari estaria, para todos os efeitos de demarcação entre o Brasil e a Bolívia, situada aos 70 1' 17" de latitude Sul e $74^{\circ} 8^{\prime}$ 27" de longitude Oeste de Greenwich. Segundo o protocolo, "fica entendido que a dita linha deve partir da latitude $10^{\circ} 20^{\prime}$ Sul marcada no tratado de limites e nesta conformidade procederá a Comissão Mista à demarcação dos limites e colocação dos marcos destinados a indiciar os pontos de intersecção" (Brasil, 1894, p. 165).

O chefe da primeira comissão brasileira no período republicano foi o coronel Gregório Thaumaturgo de Azevedo, nome sempre lembrado nos episódios que se seguiram por ter contestado a interpretação ministerial do Tratado de 1867 e por ter manifestado o seu desacordo na imprensa. Conjunturas conturbadas podem possibilitar a criação de cenários em que as ações individuais se destaquem. Sem sombra de dúvidas, este foi o caso de Thaumaturgo na questão do Acre. Entretanto, deve-se sublinhar o fato de ele ter sido o primeiro a ir, em missão oficial, a essa área que estava na iminência de conflito, tendo que realizar a parte técnica de um Tratado pouco claro e que possibilitava várias interpretações sobre o traçado da linha geodésica? ${ }^{7}$. Talvez por isto, o seu nome seja mais associado às polêmicas políticas do que ao seu trabalho técnico-científico.

Ao seguir as instruções do protocolo que tinha em mãos, que fixava a nascente em 70 1', Thaumaturgo ressaltou em correspondência com o ministério que isto subtrairia ao território nacional uma grande área já povoada por brasileiros. Ele descobriu vários pontos duvidosos na demarcação feita pelo Barão de Tefé e, em ofício ao ministro, datado de julho de 1895, informava ter notícias por fonte segura de que "a nascente do Javari estava muito acima da latitude achada [por Tefé]" (Brasil, 1897, p. 7). Não querendo continuar uma obra de valor discutível, considerou que as

5 Pesquisa realizada nos protocolos da Segunda Comissão de Demarcação e Levantamento, no Rio de Janeiro, do Ministério das Relações Exteriores, em 2009.

6 Designa acordos menos formais que os tratados, ou acordos complementares de um tratado ou convenção, ou ainda acordos interpretativos de ato anterior. O protocolo não pode contradizer o tratado diplomático a que está referido (Brasil, 2008).

7 Em um documento encontrado na seção de manuscritos da Biblioteca Nacional, há um exercício do Barão Ponte Ribeiro de como seria o traçado de limites na Amazônia, entre o Brasil e a Bolívia. Tudo dependia da localização das nascentes do Javari, se mais ao sul a linha seria uma oblíqua, se coincidente ao paralelo $10^{\circ} 20^{\prime}$ seria uma reta.

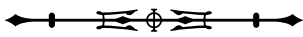


nascentes do Javari the pareciam estar situadas em zona mais ao sul do que a estabelecida no protocolo de 1895. Segundo o mesmo relatório, "o coronel Thaumaturgo de Azevedo avaliou em 5.870 léguas quadradas o território perdido pelo Estado do Amazonas, em consequência do suposto erro de latitude. Era, na verdade, uma perda assustadora" (Brasil, 1897, p. 7). Entretanto, lá estando, procedeu a uma viagem demorada no alto Juruá, explorando os rios Gregório, Ipixuna e Purus, estabelecendo marcos.

Em novembro de 1895, a comissão mista reuniuse em Caquetá, à margem do rio Acre, com o objetivo de dar início aos trabalhos de demarcação. A comissão havia aprovado um quadro geral das latitudes médias para longitudes de 10' em 10' da linha geodésica do Madeira ao Javari. Mas houve divergência entre os comissários quanto à longitude de Caquetá e, tendo começado a estação de chuvas, Thaumaturgo retornou para Manaus a fim de regular seus cronômetros e retomar um pouco mais tarde os trabalhos de demarcação. Depois, por conta de muitas dificuldades, tais como impossibilidade de transporte de víveres em canoas, fome, doença do pessoal e desacordo com o comissário boliviano, Thaumaturgo foi para Belém e de lá escreveu uma carta ao ministro solicitando sua demissão, alegando razões de saúde (Brasil, 1897, p. 11-12).

Quando retornou ao Rio de Janeiro, fez severas críticas na imprensa ao ministro Carlos de Carvalho e a seu sucessor, Dyonísio Cerqueira. Ainda nesse contexto, surgiu o livro de Serzedelo Corrêa - "O Rio Acre" -, dedicado ao próprio Thaumaturgo (Corrêa, 1899), que dividiu a opinião pública e sensibilizou a nação para o problema dos brasileiros lá residentes.

Em uma série de artigos publicados na imprensa entre os anos 1900 e 1901, Thaumaturgo de Azevedo expressou seu ponto de vista em desacordo com o ministro Dyonísio Cerqueira, atribuindo a este ignorância da parte técnica concernente aos trabalhos de delimitação, como, por exemplo, o emprego do azimute para a determinação da latitude e as equações do raio equatorial, elementos fundamentais para os cálculos geodésicos (Azevedo, 1901). Contudo, a tônica de seus artigos residia na ênfase nos aspectos políticos e na denúncia da inoperância do governo do Brasil em defender os interesses de seus compatriotas naquela região. A leitura dos mesmos oferece poucos elementos para a compreensão dos aspectos técnico-científicos da expedição. Talvez, a efervescência política que este assunto despertava tenha resultado na pouca atenção dada pela historiografia a esta comissão, enquanto expedição científica. Um exemplo da retórica utilizado pelo coronel na imprensa e em seus escritos pode ser encontrado na seguinte passagem:

\begin{abstract}
Foi já em 1895 que o nosso ministro Carlos de Carvalho, entrando em negociações, assinou com o plenipotenciário da Bolívia, F. Diez de Medina, o célebre protocolo de 19 de fevereiro, cujo art. 2 é a origem de todos os males à população do Acre, dos vexames por que tem passado a nossa chancelaria, dos prejuízos suportados pelo Amazonas, ocasionados ao comércio, à liberdade de trabalho, à ordem social, fator de todos os atentados - a invasão do nosso território, o eclipse da nossa soberania, veículo de todas as desgraças - o sangue e o luto, a viuvez e a orfandade! (Thaumaturgo de Azevedo apud Gonçalves, 1901, p. 35).
\end{abstract}

No entanto, isto não significa que a viagem de Thaumaturgo de Azevedo fosse desprovida de interesse científico. No Arquivo do Museu Nacional existe uma relação de nove caixas de amostras colhidas na região por ocasião daquela viagem. Nestas caixas, há exemplares da fauna, da flora e etnográficos, tais como pele de jiboia, pedras de amolar dos índios 'Jamandys', vidros com peixes e serpentes, além de diversos exemplares de madeiras do rio Purus. Cabe lembrar que esta iniciativa 'naturalista' do coronel não foi espontânea, mas obedecia a uma solicitação do Ministério dos Negócios Interiores ao Ministério das Relações Exteriores. Uma vez que a comissão de demarcação iria percorrer uma região pouco explorada, que seus membros também fossem encarregados de "adquirir espécimes naturais 
que venham enriquecer as coleções existentes nesse estabelecimento [Museu Nacional]"8.

Além dos naturalistas do Museu Nacional, o Ministério da Guerra também fez demandas aos expedicionários que se encontravam nas proximidades da fronteira. $O$ ministro da Guerra, Bernardo Vasques, solicitou que escolhessem pontos mais próximos da fronteira "para o estabelecimento de postos militares" (Vasques, 1895, p. 1). Esta notícia publicada no "Jornal do Commercio" lembrou que, se a comissão era de responsabilidade do Ministério das Relações Exteriores, a mesma também poderia ser tida como militar por contar com oficiais em seus quadros. Assim, entende-se a organização destas comissões como uma justaposição de funções, partindo sempre do princípio de que o território brasileiro era vasto e inexplorado em sua totalidade, em um momento de precárias vias de comunicação. Nesse sentido, as viagens científicas eram vistas como uma oportunidade de preencher estas lacunas. O estudo destas comissões dá subsídios para uma história da ciência no Brasil, na qual se pode compreender a dinâmica interna de expedições que mantêm entre si semelhante estrutura, apesar de diferentes objetivos.

\section{AUGUSTO CUNHA GOMES}

Thaumaturgo de Azevedo não produziu um relatório oficial de sua viagem. Ao se desligar da comissão mista, seu substituto, o segundo comissário Augusto Cunha Gomes, foi nomeado chefe da comissão em 1898. Seu relatório "Reexploração do Javari" é considerado o texto final da comissão. Isto fez com que a historiografia percebesse as duas viagens, tanto a de Thaumaturgo quanto a de Cunha Gomes, como a mesma comissão. Todavia, para melhor atingir os objetivos propostos neste artigo, optou-se por analisar as viagens como comissões separadas.

Dos relatos estudados, o que mais trouxe informações sobre a região foi o do capitão-tenente Cunha Gomes. Sua missão era conferir os cálculos da comissão exploradora do rio, realizada em 1874 pelo Barão de Tefé. O relato de Cunha Gomes apresentou o rio Javari como sendo bastante povoado e navegado com regularidade até um determinado ponto, Remate de Males. Da confluência com o rio Galvez em diante, a viagem se tornava fatigante e trabalhosa. As margens do rio Javari são descritas como ricas em seringais.

No item sobre o clima, Cunha Gomes expôs como faria as observações climatológicas. A ideia seria fazer observações com regularidade, aferindo as temperaturas diárias máximas e mínimas, bem como o grau higrométrico do ar (umidade relativa) e a pressão atmosférica. Isso não foi possível porque o tempo de observação era insuficiente. Assim sendo, o chefe da comissão utilizou a fórmula de Emmanuel Liais (1826-1900), antigo diretor do Imperial Observatório nos anos de $1880^{\circ}$, para a determinação da temperatura média anual, que leva em consideração a latitude do lugar.

Em suas observações, Cunha Gomes afirmou que aquela região era por demais úmida, favorecendo a noção de que era um local insalubre. Lá encontrou diversos casos fatais de doenças em uma população que buscava trabalho e fortuna, segundo suas palavras, mas não possuía meios para obter alimentação e habitação adequadas, ficando exposta às febres e outras doenças tropicais. Para se prevenir daquele quadro nosológico, os membros da comissão receberam de seu médico, Dr. Bulcão Viana, preparados arsenicais e quinino, que garantiram a profilaxia das doenças da região, tendo o capitão-tenente registrado apenas uma morte por beribéri, a do marinheiro Aleixo. A matéria publicada no "Jornal do Commercio" em 19 de junho, sobre a comissão demarcadora de 1897, informou que o mesmo médico já havia prestado relevantes serviços ao país durante a revolução do Rio Grande do Sul. $\bigcirc$ artigo é concluído com palavras de boa sorte para a comissão chefiada por Cunha Gomes: "Desejamos que sejam coroados de feliz êxito os sacrifícios, que, em prol

\footnotetext{
8 Carta de 14 de maio de 1895 [assinatura ilegível]. Secretaria da Justiça e Negócios Interiores, Capital Federal, pasta 34, doc. 92. Arquivo do Museu Nacional. Pesquisa realizada pelo bolsista FAPERJ/MAST Luis Felipe Trotta.

9 Para maiores informações sobre a importância de Liais e a climatologia no Brasil, ver Barboza (2002).
}

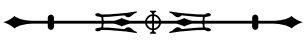


da ciência, vão ser feitos por este punhado de ilustres brasileiros" (Comissão..., 1897, p. 2).

Do ponto de vista etnográfico, o relatório se refere aos índios como os "selvagens do Javari". Afirma que estes sempre foram ferozes e bravios, sendo responsáveis pela morte do astrônomo Soares Pinto, da comissão brasileira de 1874, e pela do geógrafo peruano Paz Soldan. No momento em que escrevia, Cunha Gomes informava que o número de índios era reduzido principalmente devido às lutas com os caucheiros peruanos. No baixo Javari, ele encontrou índios das tribos Marungo e Tucuna. Contudo, foram os índios Capananas que mereceram descrições pormenorizadas, considerados os responsáveis pelos momentos mais tensos da viagem. Tidos como canibais e ferozes, perseguiram a comissão desde o rio Galvez até o Javari. Por medo de ataque, os soldados da comissão dispararam tiros até que os índios se retirassem.

A flora, a fauna e a geologia também figuram no relatório: a região é apresentada como rica em madeiras de lei, além da seringueira. Havia diversos tipos de macacos e onças, várias espécies de pássaros. Segundo as observações de Cunha Gomes, não foi encontrado nenhum fóssil no vale do Javari e, por conta da missão se destinar à determinação das nascentes, não foi possível procurar "petrefactos" que deveriam contar as camadas de aluvião, impossibilitando a determinação da idade geológica do vale. Entretanto, pela natureza de sua construção, verificada pela comissão nos cortes das margens, e pelos fósseis achados por William Chandless ${ }^{10}$ no Juruá, vale vizinho ao do Javari, Cunha Gomes afirmou que "parece pertencer ao sistema devonio siluriano" (Brasil, 1898, p. 390).

A parte concernente à astronomia encontra-se no item "Cronometria". Neste relatório, Cunha Gomes explicou que "o conhecimento da posição de um ponto qualquer da terra se reduz à determinação de sua latitude, longitude, azimute ou direção do meridiano e sua altitude" (Brasil, 1898, p. 258). O capitão-tenente relembrou que os cronômetros ou relógios de marinha estão ligados à história da navegação desde o século XVIII e que, aperfeiçoados, estavam sendo também utilizados para determinação das posições geográficas. A longitude foi calculada por meio deste instrumento através da comparação da hora do primeiro meridiano em relação a um meridiano de origem, como o de Greenwich. Para que tal cálculo fosse correto, era preciso que o cronômetro tivesse uma marcha uniforme. Mas as condições da viagem impediram o perfeito andamento do instrumento. Assim, foi preciso fazer constantes observações astronômicas com lunetas e sextantes para a regulagem dos cronômetros. A relação entre a longitude e o tempo se dá pelo fato de a Terra levar 24 horas para completar uma revolução de 360 graus, sendo uma hora equivalente a 1/24 da revolução ou quinze graus. Assim, cada hora de diferença entre o ponto a ser marcado e o ponto original registra quinze graus de longitude para leste ou oeste (Sobel, 2008, p. 13).

Um exemplo de como a astronomia foi utilizada para a verificação de uma coordenada geográfica está na verificação de Cunha Gomes do ponto atribuído pelo Barão de Tefé como a nascente do Javari. Segue o capitão-tenente:

Nesse lugar nos demoramos três dias e durante esse tempo fizemos observações de série de alturas do sol, passagem meridiana das estrelas Altair e Wega e circum-meridianas do sol e dos resultados obtidos tomamos a medida seguinte: lat. $7^{\circ} 01^{\prime} 21^{\prime \prime} \mathrm{S}$ e long. $73^{\circ} 43^{\prime} 21^{\prime \prime} \mathrm{OW}$ Gw. Estávamos, portanto, no paralelo onde pela comissão de 1874 devia achar-se a nascente do Javari (...) (Brasil, 1898, p. 271).

Cunha Gomes corrigiu as coordenadas do Barão de Tefé verificando uma diferença de quase quatro segundos. Percebeu que o rio Javari era um prolongamento do Jaquirana e não do Galvez, como afirmava a comissão de 1874. Ao demonstrar como fizera as observações astronômicas, o capitão-tenente possibilitou que qualquer um que possuísse o conhecimento necessário pudesse

10 William Chandless nasceu em Londres em 1829 e lá morreu em 1896. Nos anos de 1860, explorou a bacia do Amazonas e escreveu uma memória sobre o vale do Purus para a Royal Geographical Society, trabalho este lido e bastante citado por Euclides da Cunha em seu relatório de 1906 sobre a viagem à mesma região (Cunha, 1906).

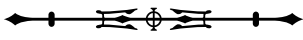


conferir seus cálculos. Cabe lembrar que a linha geodésica que divide os estados do Amazonas e Acre recebe o seu nome. Por conta das alterações dos últimos anos, atualmente é conhecida por Nova linha Cunha Gomes. Apesar dos esforços do capitão-tenente, a determinação das coordenadas das nascentes não foi aceita pelo governo boliviano, pois o comissário boliviano não estava presente no momento em que o brasileiro lá chegou. Para todos os efeitos, o governo boliviano ainda estava utilizando as coordenadas da expedição do Barão de Tefé.

Ao mesmo tempo em que estes trabalhos de campo estavam sendo desenvolvidos, o conflito entre brasileiros e bolivianos se agravava. Não há nenhuma notícia destes incidentes nos relatórios técnicos de Cunha Gomes, mas enquanto estava na Amazônia, a Bolívia obteve do governo brasileiro, em setembro de 1898, permissão para instalar uma alfândega no Acre (Sena, 2002, p. 17), considerada o estopim da 'revolução acreana'.

\section{LUIZ CRULS}

A falta de acordo entre os governos sobre o local da nascente do Javari gerou alguns conflitos. Segundo o Tratado de 1867, até aquele momento em vigor, o limite entre os dois países poderia ser uma paralela ou uma oblíqua. Valendo-se da interpretação de que aquela região era boliviana, o governo brasileiro, como dito anteriormente, anuiu na abertura de uma alfândega boliviana em uma área povoada por brasileiros, Porto Alonso. Neste cenário, surgiu a figura de Luis Galvez Rodriguez de Arias (1864-1935), que se auto-proclamou presidente do Estado Independente do Acre, o que, de certa forma, ameaçava a soberania do Brasil. Diversos intelectuais da época se pronunciaram sobre o caso, como Rui Barbosa, Paula Freitas, Paulo de Frontin e Euclides da Cunha (Sena, 2002, p. 9).

Em 1899, o governo boliviano "expedia uma coluna militar até a fronteira brasileira" para fazer valer os seus direitos em uma área em litígio (Sena, 2002, p. 10). Em meio a estes acontecimentos, o Relatório Ministerial expressava a necessidade de se realizar observações astronômicas exatas (Brasil, 1899, p. 6). Por esta razão, no mesmo documento há a nomeação do astrônomo Manuel Pereira Reis (1837-1922), diretor do Observatório da Escola Politécnica, como chefe da comissão demarcadora, tendo por ajudantes Alfredo de Souza Rangel e Mario de Oliveira Roxo (Brasil, 1899, p. 14). Contudo, quem iria efetivamente chefiar esta comissão seria o diretor do então Observatório Astronômico, atual Observatório Nacional, Luiz Cruls (1848-1908), astrônomo belga naturalizado brasileiro (Barboza, 2004).

Em 1901, o ministro das Relações Exteriores, Olyntho de Magalhães, deu a Cruls instruções para subir o rio Javari até as nascentes e determinar sua verdadeira posição geográfica. Segundo Olyntho de Magalhães, a situação do Acre era complicada:

O seu território é habitado, não por bolivianos, [mas] por brasileiros, que nem um interesse real tem na sua independência, porque não lhes muda a sorte. Eles são, como antes, simples instrumentos na exploração de seringais, mais sujeitos à fatal consequência da insalubridade do clima que enriquecidos pelo trabalho (...) (Olyntho de Magalhães apud Goycochêa, 1973, p. 39).

Luiz Cruls, quando foi à Amazônia, já tinha seu nome firmado como um importante cientista, inclusive pelas muitas viagens que fez, como a de exploração do Planalto Central, em 1892, trabalho pelo qual é atualmente mais conhecido. Todavia, a experiência de Cruls com os trabalhos de geodésia não se restringe a este evento. Sua primeira atuação profissional no Brasil foi como membro da comissão da Carta Geral do Império, de 1875, na seção de geodésia, na qual teve, entre as suas atribuições, a de comprar instrumentos científicos na Europa. Além disso, era professor de geodésia da Escola Militar. Cruls tinha plena consciência da importância daquela região para a geopolítica brasileira, chegando a citar a doutrina Monroe para afirmar que, se a América era dos americanos, a Amazônia deveria pertencer ao Brasil (Cruls, 1904, p. 186). 
Sua missão era, além de determinar a posição geográfica das nascentes do rio Javari, traçar a linha geodésica entre este rio e o Madeira. Para esta última etapa, segundo as ordens ministeriais, deveria voltar a Manaus e aguardar instruções ${ }^{11}$. Olyntho de Magalhães temia que os "trabalhos de demarcação ocasionassem conflitos em que até corressem risco de vida os comissários e o pessoal que os acompanhasse" (Brasil, 1900, p. 6). Nesse sentido, dizia o ministro: "Portanto, sou obrigado a determinar ao Comissário Brasileiro que, feita a verificação relativa à nascente do Javari e firmada a ata respectiva, regresse a Manaus para aí receber as minhas últimas ordens" (Brasil, 1900, p. 7).

Segundo essas instruções, a comissão mista seria instituída em 15 de janeiro de 1901 em Belém, após os comissários reconhecerem mutuamente os seus poderes e mediante a assinatura da ata. $\bigcirc$ pessoal que compunha a comissão brasileira era assim composto: capitão de fragata Carlos Accioli; capitão do Estado-Maior Augusto Tasso Fragoso; Dr. Leovigildo Honorário de Carvalho, médico; capitão farmacêutico Alfredo José Abrantes; capitão honorário Eduardo Chartier; secretário Ricardo Veríssimo Vieira; encarregado do material Arthur Nogueira; e um contingente militar de 50 praças, comandados pelo Alferes Arthur Cantalice.

A escolha de Cruls foi positivamente saudada pelo "Jornal do Commercio", que expressava a confiança de que a comissão técnica iria solucionar a questão dos limites com a Bolívia. O artigo de 22 de fevereiro de 1901 prestou homenagem ao chefe da comissão, descrevendo-o como figura de "elevada estatura profissional" e "reputada autoridade em assuntos astronômicos e geodésicos", lembrando também de sua "competência e méritos científicos comprovados em trabalhos transcendentes conhecidos no Brasil e no estrangeiro" (Gazetilha, 1901a). O texto enumera as comissões desempenhadas pelo ilustre astrônomo e finaliza assegurando que a comissão mista daria uma prova última de sua competência. Já como chefe da Comissão Brasileira, Luiz Cruls partiu do Rio de Janeiro em 4 de janeiro de 1901 e chegou no dia 20 no Pará, percorrendo a costa brasileira.

Se comparado ao da expedição de Cruls ao Planalto Central, o relatório da viagem de 1901 é totalmente diferente. No primeiro, há uma introdução que explica para o leitor os fatores que motivaram a viagem e possui uma descrição detalhada da região explorada, além de farto material fotográfico, segundo as características dos relatórios das expedições científicas da República já expostos por Figueirôa (2008). O da Comissão de Limites, publicado em 1902, possui um perfil mais técnico, expondo os problemas da viagem, como a preocupação com possíveis ataques de índios, a interferência de representantes do governo do Peru, as dificuldades com embarcações e com doenças da comitiva.

É importante sublinhar que, neste relatório, podese acompanhar passo a passo como as observações astronômicas foram feitas e quais instrumentos foram utilizados. Deste ponto de vista, o relatório é uma fonte bastante valiosa para se entender como a astronomia era utilizada nos trabalhos de demarcação. Tendo em vista que o objetivo da missão era verificar os cálculos já realizados por Cunha Gomes, este relatório se refere constantemente aos trabalhos de seu predecessor, tornando imprescindível a leitura do anterior para a compreensão do mesmo.

Quando se põem lado a lado os relatórios de Cunha Gomes e de Cruls, nota-se que o último é mais detalhado e mais preciso quanto ao relato de suas observações astronômicas. Esta preocupação em mostrar a exatidão

\footnotetext{
11 Havia, em outubro de 1899, uma instrução para a comissão mista verificar a verdadeira posição geográfica do Javari e demarcar a linha divisória entre esse rio e o Madeira. Esta foi substituída por outra, de agosto de 1900. A substituição de instruções não agradou ao Clube de Engenharia. Seu presidente, Paulo de Frontin, mandou ao presidente da República uma moção solicitando que se utilizasse a instrução de 1899, e não a de 1900, por considerar a última inexequível, pois instruía a determinação do Jaquirana e não a do Javari, além de haver uma discordância com relação aos valores atribuídos ao raio terrestre ou, nos termos da instrução, ao achatamento da Terra, considerado como 1/295 (Manuscrito, Clube de Engenharia).
}

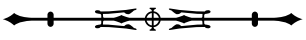


dos cálculos pode ser simplesmente interpretada pelo fato do segundo ser um dos principais astrônomos daquele momento no Brasil, bem como uma estratégia para se defender de eventuais críticas.

Antes mesmo de assumir a comissão de 1901, Cruls já havia se manifestado sobre a questão dos limites com a Bolívia. Quando responsável pela seção Revista Científica da "Revista Brasileira”, em 1897, ele aproveitou os debates para explicar uma questão mais complexa da geodésia, ou seja, o cálculo das longitudes. Cruls explicou que, para a determinação da longitude, era preciso tomar um ponto da Terra já conhecido, que seria o meridiano inicial, e outro cuja longitude está ainda para ser calculada. Para a execução de tal método, também era preciso ter a hora certa, pois longitude é a coordenada geográfica que leva em consideração a rotação da Terra, ou seja, o tempo gasto pela superfície do planeta para percorrer o espaço entre a longitude 0 (atualmente Greenwich) e o ponto que se deseja determinar:

Pode-se, grosso modo, calcular a longitude levando em consideração que cada hora representa $15^{\circ}$, ou seja, no caso do Rio de Janeiro em relação a Greenwich, temos $3 \mathrm{~h}$ a menos de diferença, o que significa que estamos a $45^{\circ}$ de longitude oeste (Cruls, 1897, p. 372).

Este procedimento, conhecido por 'transporte da hora', era difícil para o caso do limite com a Bolívia, uma vez que, para manter a hora certa, era preciso fazer constantemente observações astronômicas, pois os relógios com frequência se desregulavam devido à umidade, e não havia telégrafo para se obter a hora de um observatório. Cabe lembrar que os instrumentos levados pela comissão de 1897 pertenciam ao Observatório Astronômico do Rio de Janeiro, instituição da qual Cruls era diretor. Assim, ele concluiu aquele artigo afirmando que, se houve "desacordo que motivou a suspensão dos trabalhos" (Cruls, 1897, p. 374), isto não se devia à versão que circulava na imprensa, de que a diferença de cálculo entre os comissários resultava de os nacionais terem seus aparelhos calibrados no Observatório do Rio de Janeiro, enquanto os bolivianos o fazerem em Londres. $\bigcirc$ diretor do Observatório afirmou que os instrumentos não poderiam ser responsabilizados pelas desavenças, já que sua regulagem obedecia a critérios científicos universais, válidos tanto para o Brasil quanto para a Bolívia.

Desembarcada a comissão em Belém a 21 de janeiro de 1901, resolveu Cruls montar o seu observatório no interior do Forte do Castelo, pois era um lugar onde a iluminação elétrica da cidade não interferia na observação astronômica. Durante este período, escreveu o artigo "Climatologia do Amazonas", publicado no jornal "A Federação" e depois em um jornal local, no qual afirmou:

É necessário dizê-lo e afirmá-lo de modo categórico: o clima da Amazônia há sido muitíssimo caluniado. Não quer dizer que ela goze de condições climáticas e de salubridade isenta de defeitos. Mas onde em toda a superfície do globo, se encontrará porventura, algum clima que não tenha defeitos? Em parte nenhuma (Cruls, 1901, grifo nosso).

A repetição do termo "clima caluniado" surgiria anos mais tarde como título de artigo e depois como capítulo do livro "À Margem da História", de Euclides da Cunha, mas este texto não fez nenhuma referência a $\mathrm{Cruls}^{12}$. Ambos partem da mesma ideia de que o clima não era favorável, mas que a ação do homem poderia transformar e civilizar a região. Cabe lembrar que Cruls, que fora professor de Euclides da Cunha na Escola Militar, aconselhou-o a ir ao Amazonas para chefiar a já mencionada comissão de reconhecimento do alto Purus, em 1904. Como "Os Sertões", "À Margem da História" foi escrito a partir da experiência profissional de Euclides, que buscava estabelecer em sua obra uma inter-relação entre a expressão literária e a ciência (Cunha, 2005).

\footnotetext{
12 A referência ao termo "clima caluniado" como proveniente de Luiz Cruls foi sublinhada por Elói Pontes em "A Vida Dramática de Euclides da Cunha", segundo o literato Gastão Cruls no perfil biográfico que fez sobre o seu pai para a edição do livro "Planalto Central do Brasil" (Cruls, 1957).
}

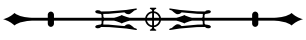


Para executar sua missão, Cruls precisava determinar corretamente as coordenadas de uma cidade próxima, no caso, Belém, e a partir de lá continuar seu trabalho de levantamento. O diretor do Observatório saiu do Rio de Janeiro com as coordenadas de Belém estabelecidas pelo "Telegraphic measurement of differences of longitude", da Marinha norteamericana, de 1879. Entretanto, ao se estabelecer na capital do Pará e montar seu observatório no Forte do Castelo, observou que aqueles cálculos estavam errados, e logo informou ao Navy Department, em Washington, que aceitou as correções de Cruls. Em seu relatório de 1902, este foi o primeiro fato relatado, com repercussão na imprensa nacional, como uma matéria de primeira página no "Jornal do Brasil", de 4 de abril de 1901, na qual afirmava: "O departamento naval de Washington verificou os cálculos [de Cruls], e deu razão à comissão brasileira". A mesma notícia seria veiculada somente um mês depois, em 13 de maio, na segunda página do "Jornal do Commercio", acrescentando que estas coordenadas "serão necessárias para o início dos trabalhos da comissão de limites com a Bolívia, conforme determinam os protocolos" (Gazetilha, 1901b, p. 2). Este pequeno 'triunfo' da ciência nacional reforçou, na imprensa, a imagem de competência científica do chefe da comissão.

Parte do tempo gasto em Belém foi utilizada para a construção de canoas para subir o Javari, cuja vazante ia tornar indispensável o uso de pequenas embarcações. Nesta cidade, iniciaram-se os trabalhos da comissão mista com a chegada dos comissários bolivianos. Procedeu-se à comparação dos estados absolutos dos cronômetros, "sendo em ambos os casos as diferenças encontradas inferiores a seis décimos de segundo" (Cruls, 1902, p. 5). Este procedimento fazia parte dos trabalhos das comissões mistas: as comissões nacionais viajavam separadamente e se reuniam em locais pré-determinados ao longo do percurso para comparar os dados aferidos, incluindo a verificação dos instrumentos, como os cronômetros. Os cálculos acordados entre as duas comissões eram os resultados, lavrados em atas, da comissão mista. Cruls descrevia assim o seu trabalho:
As observações feitas pelas comissões brasileiras e bolivianas foram de modo absolutamente independente, com instrumentos e por processos distintos, e dos resultados, comunicados somente na ocasião das conferências, foram tomadas as médias, logo que as diferenças entre os resultados obtidos por ambas as comissões não excediam os limites dos erros toleráveis, o que foi sempre o caso, tanto nos trabalhos executados no Pará e em Tabatinga, como no Galvez, na confluência do Rumyaco [sic] com o Jaquirana, e nas nascentes principais do Jaquirana (Alto Javari) (Cruls, 1902, p. 14).

Inicialmente, Cruls pretendia verificar a longitude das coordenadas que deveria estabelecer através do método telegráfico, isto é, receberia a informação da hora do Observatório Astronômico e, determinando a diferença entre a hora local e a hora do Rio de Janeiro, registraria a longitude. Entretanto, o cabo subfluvial rompeu-se e não foi possível assim proceder, restando ao astrônomo fazer todos os cálculos a partir de observações astronômicas no local. Nesse sentido, é impraticável pensar em uma história da cartografia sem levar em consideração o telégrafo, não apenas como símbolo de civilização, mas como aparato imprescindível para a produção e aplicação da ciência no território brasileiro no começo do século $X X$.

Simultaneamente a esta expedição, a região do Acre estava passando por conflitos, a 'revolução acreana'. Em seu relatório, Cruls não fez menção a este fato, talvez por interpretar que tal questão era de ordem políica e que nada tinha a ver com os seus trabalhos de natureza técnica. Contudo, ele relatou sua experiência com os índios, que também causaram graves momentos de tensão na comissão anterior.

Na madrugada de 19 a 20 de agosto, os índios haviam dado cerco a um barracão, denominado São Jorge (...) e exterminado todos os moradores, em número de 16. Essa tribo não usa nem o arco, nem lança, mas unicamente sabres, bastante afiados, feitos de madeira dura e resistente. Visitamos o barracão S. Jorge, e aí encontramos numerosas e inequívocas provas do hediondo morticínio perpetrado dias antes (Cruls, 1902, p. 24).

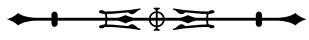


Se no relatório de Cunha Gomes encontra-se o nome das tribos e a descrição de seus costumes, Cruls os chama genericamente de 'índios'. A solução encontrada pelo chefe da expedição de 1901 para evitar o confronto com os indígenas foi explodir uma ou duas bombas de dinamite nos acampamentos para mantê-los afastados do pessoal da comissão.

No dia 28 de agosto de 1901, a Comissão Mista Brasil-Bolívia ergueu um marco de ipê nas coordenadas $7^{\circ}$ $6^{\prime}$ de latitude e $73^{\circ} 47^{\prime}$ de longitude na nascente principal do rio Javari, com uma cerimônia que contou com salvas de tiros e com o hasteamento das bandeiras nacionais, cumprindo, assim, o primeiro de seus objetivos. Segundo o relatório de 1902, faltava ainda proceder a demarcação da fronteira, como constava na primeira ata de reunião da Comissão Mista. O comissário representante do governo boliviano, o inglês C. Satchell, expressava o desejo de que o Protocolo de 1900 fosse obedecido e que se fizesse logo a demarcação. Cruls, por sua vez, afirmou que não o faria por aguardar ordens do governo brasileiro (Cruls, 1902, p. 132), alegando também discordâncias técnicas com a Comissão Boliviana para o estabelecimento da linha geodésica. Em seu relatório, Cruls não fez menção a questões de conjuntura política, como era de seu estilo, mas pode-se considerar que não efetuou a nova demarcação por causa da revolução acreana, que, segundo Raja Gabaglia (1916, p. 244), "imprimia direção diversa às negociações". O relatório do Ministério das Relações Exteriores de 1912, publicado após a morte do Barão do Rio Branco, narrou da seguinte forma a interrupção dos trabalhos da Comissão de 1901:

Sobrevindo a Revolução dos Acreanos, o Brasil (...) foi obrigado a intervir para proteger os seus nacionais e resolveu ocupar militarmente parte do território limitado pelo paralelo $10^{\circ} 20^{\prime}$ de latitude meridional, que declarou ser a linha divisória indicada pela letra e pelo espírito do artigo $2^{\circ}$ do Tratado de 1867, devendo essa ocupação durar até a solução do litígio por via diplomática (Brasil, 1911, p. 12).

Ademais, a ida de Cruls ao Amazonas também foi cercada de vicissitudes do ponto de vista pessoal: ficou doente e nunca mais recuperou sua saúde, falecendo, em 1908, muito provavelmente em decorrência de doença tropical lá contraída. A memória desta viagem foi assim registrada no Exército, em uma conferência no dia do soldado: "Já velho e infectado pelo terrível mal daquelas regiões, não houve fadiga que o abatesse. Sabe-se que na última jornada foi conduzido por quatro homens em uma cadeira improvisada por não poder se manter de pé" (Guimarães, 1940, p. 24).

Entre os três chefes de comissões delimitadoras, Cruls era o 'cientista' no sentido mertoniano, ao buscar uma imagem de figura 'desinteressada' dos assuntos políticos, cuja única preocupação seria com o avanço da ciência. Como os demais comissários, Cruls também escreveu para a imprensa, em jornais e revistas, mas sempre com o intuito de divulgar a ciência, explicando para o público leigo os conteúdos científicos, como foi o caso da "Revista Brasileira", ou explicitando os percalços da prática científica das comissões demarcadoras, como fez na revista "Renascença".

Na leitura do "Jornal do Commercio" ao longo do ano de 1901, nota-se que várias críticas foram surgindo, principalmente quando Cruls demonstrou uma discrepância em relação ao seu antecessor de quatro minutos de longitude. Um destes críticos foi o astrônomo Manuel Pereira Reis, que fez um discurso na Câmara, na qualidade de deputado, criticando a comissão chefiada por Cruls, considerando os seus trabalhos "incompletos e duvidosos", defendendo os cálculos de Cunha Gomes e aconselhando o governo a extinguir a comissão de 1901 (Oliveira e Videira, 2003, p. 49). Segundo notícia publicada no "Jornal do Commercio", os cálculos de Cruls significavam a perda de 100 léguas em favor da Bolívia (Gazetilha, 1901b).

Sobre a sua missão ao Javari, Cruls enviou uma nota para a seção de correspondência da revista científica "Bulletin Astronomique", na qual descreveu sua expedição para o matemático Henri Poincaré (18541912). Além de divulgar os seus cálculos da nascente principal daquele rio, Cruls relatou as condições de viagem, trazendo a questão do clima à cena mais uma

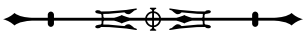


vez, neste momento com um olhar diferente do que fez para o jornal "A Federação":

As más condições climáticas da região percorrida foram a causa, durante a viagem de volta, do sofrimento do contingente da comissão; as febres, o terrível beribéri, nos levaram um dos membros da missão brasileira, o capitão de fragata Carlos Accioli, o capitão do contingente militar e uns vinte homens da equipe. O próprio chefe da missão foi acometido de violentos acessos de febre quase fatais (Cruls, 1903, p. 17).

Na historiografia da ciência no Brasil, há uma interpretação de que a viagem de Cruls foi importante para a elaboração do Tratado de Petrópolis ${ }^{13}$. Talvez a sua importância como cientista e o tratamento dado à comissão na imprensa tenham contribuído para esta visão. Entretanto, na Exposição de Motivos sobre o Tratado de 1903, é possível ver que o Barão de Rio Branco optou por uma condução política para a crise, fazendo tabula rasa das viagens de demarcação do período republicano. Os acontecimentos políticos, precipitando-se, haviam tornado sem efeito os esforços técnicos de localização precisa das nascentes do Javari. Cabe a ressalva de que, apesar dos trabalhos de Luiz Cruls não terem sido utilizados no Tratado de Petrópolis, isto não os invalida. As coordenadas que sua comissão determinou para as nascentes do rio Javari, consideradas a parte mais ocidental do Brasil, foram as mesmas utilizadas em importantes obras que tinham por objetivo apresentar a geografia do país, como o "Dicionário Histórico, Geográfico e Etnográfico do Brasil", publicado para as comemorações do Centenário da Independência de 1922 (IHGB, 1922).

\section{CONSIDERAÇÕES FINAIS}

Para descrever o ambiente nos anos de 1900 acerca da questão do Acre, melhor utilizar as palavras do barão do Rio Branco:
Na Bolívia, preparavam expedições militares para levantar o assédio dessa praça, submeter os acreanos e dar posse ao Sindicato [Bolivian Syndicate]. Entre nós, homens eminentes, no Congresso, na imprensa e em sociedades científicas, combatiam desde 1900 a inteligência oficialmente dada ao tratado de 1867, e sustentava que a fronteira estipulada não era a linha oblíqua ao Equador, mas sim a do paralelo de $10^{\circ} 20^{\prime}$. A opinião, fortemente abalada, pedia que o território compreendido entre as duas linhas e a fronteira com o Peru fosse reivindicado pelos meios diplomáticos ou pelos mais enérgicos de que pudesse dispor o Governo (Barão do Rio Branco, 1903, p. 17, grifo nosso).

O barão do Rio Branco utilizou em seu texto complementar ao Tratado de Petrópolis os termos "opinião, fortemente abalada", e ainda: "O sentimento público entre nós era outro elemento que não podia deixar de ser tomado em consideração" (Barão do Rio Branco, 1903, p. 17), fazendo crer que, naquele movimento, o peso do que hoje se chama 'opinião pública' era bastante forte. Ele se mostrou sensível a estes apelos dizendo que observou, ao voltar da Europa, "uma unânime simpatia nacional pelos nossos compatriotas que se batiam no Acre" (Barão do Rio Branco, 1903, p. 18). Esta argumentação foi empregada pelo Barão para evitar o arbitramento internacional, proposto por Rui Barbosa, mostrando-se solidário a um sentimento nacional difuso. Seu projeto era comprar a área em litígio como forma de terminar a contenda com o país vizinho. Contudo, apesar das estratégias políticas que aquelas frases possam ocultar, o seu uso não é desligado da realidade. Os termos "sentimento público", "simpatia nacional" e "opinião fortemente abalada" remetem à ideia de uma sociedade civil relativamente organizada e dinâmica, que se forma muitas vezes em oposição ao Estado.

A historiografia da ciência no Brasil tem prestado pouca atenção à complexidade da sociedade brasileira,

\footnotetext{
${ }^{13}$ Esta versão está no livro de Videira (2003, p. 45): "A saúde de Cruls estava definitivamente comprometida depois da missão que realizara a pedido do barão do Rio Branco, então ministro das Relações Exteriores do Brasil, para a exata determinação das fronteiras entre o Brasil e o Peru em plena selva amazônica". Segundo a documentação analisada, Cruls não viajou a pedido do barão do Rio Branco e sua missão era a determinação das fronteiras com a Bolívia, e não com o Peru.
}

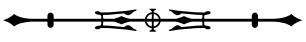


principalmente no final do século XIX. De modo geral, os agentes da ação 'civilizatória' ainda são interpretados como provenientes do Estado, deixando à margem das análises uma série de instâncias de ação da sociedade civil. O caso da fronteira amazônica entre o Brasil e a Bolívia é um interessante estudo para se observar as idas e vindas entre política e ciência e a importância da opinião pública no episódio ${ }^{14}$.

Ao analisar a construção de um setor das fronteiras brasileiras, a partir da abordagem da história da ciência, pretendeu-se contribuir para a desconstrução de uma visão da historiografia tradicional, que narra a história do Brasil como algo que se desenrola no tempo em um espaço que foi dado, sem conflitos, pelos 'desígnios da Providência'. Esta é, ainda, a ideia de que o Brasil é formado por fronteiras naturais, fornecidas pelos grandes rios do Amazonas e do Prata, ou seja, a noção de 'Ilha Brasil', existente desde o século XIX e atualizada no século seguinte por Jaime Cortesão. A análise das relações, por vezes irônicas, entre processos de decisão política e práticas científicas pode, assim, ajudar a questionar a imagem reiterada de um país cujo território seria mais uma dádiva do que uma conquista.

\section{AGRADECIMENTOS}

Ao Conselho Nacional de Desenvolvimento Científico e Tecnológico (CNPq) e à Fundação de Amparo à Pesquisa do Estado do Rio de Janeiro (FAPERJ) pelo apoio à pesquisa.

\section{REFERÊNCIAS}

ANTIBAS, Rosa Helena B. Z. Flibusteiros, não Brasileiros. Uma visão interna da questão do Acre. 2002. Dissertação (Mestrado em História) - Universidade de Brasília, Brasília, 2002.

AZEVEDO, Thaumaturgo de. Limites do Brasil. Revista Militar, v. 5, p. 462-491, 1902

AZEVEDO, Thaumaturgo de. O Acre: limites com a Bolívia. Artigos publicados n'Imprensa 1900-1901. Rio de Janeiro: Typographia Jornal do Commercio, 1901

BACKHEUSER, Everardo. Curso de geopolítica do Brasil. Rio de Janeiro: Biblioteca do Exército, 1944.
BARÃO DO RIO BRANCO. Exposição de Motivos sobre o Tratado de 17 de novembro de 1903 entre o Brasil e a Bolívia. Rio de Janeiro: Ministério das Relações Exteriores, 1903.

BARBOZA, Christina Helena. Luiz Cruls, um cientista a serviço do Brasil. Catálogo da Exposição. Rio de Janeiro: MAST/MCT, 2004.

BARBOZA, Christina Helena. Tempo bom, meteoros no fim do período: uma história da meteorologia em meados do século XIX através das obras de Emmanuel Liais. 2002. Tese (Doutorado em História Social) - Universidade de São Paulo, São Paulo, 2002.

BEAUREPAIRE ROHAN, Henrique. Relatório Final da Comissão da Carta Geral do Império. Apresentado ao Ministério da Agricultura, Comércio e Obras Públicas. Rio de Janeiro: Tipografia Nacional, 1878

BRASIL. Ministério das Relações Exteriores. Manual de Procedimentos. Brasília, maio 2008. Mimeografado.

BRASIL. Ministério das Relações Exteriores. Atas de conferências: índice geral de atas das comissões mistas de limites. Organizado por Heitor da Fontoura Rangel do Serviço dos Limites e Atos Internacionais. Rio de Janeiro: Imprensa Nacional, 1939.

BRASIL. Relatório do Ministério das Relações Exteriores. 1911. Disponível em: <http://brazil.crl.edu/bsd/u 1609>. Acesso em: 25 jun. 2009.

BRASIL. Relatório do Ministério das Relações Exteriores. 1900. Disponível em: <http://brazil.crl.edu/bsd/u 1609>. Acesso em: 25 jun. 2009.

BRASIL. Relatório do Ministério das Relações Exteriores. 1899. Disponível em: <http://brazil.crl.edu/bsd/u 1609>. Acesso em: 25 jun. 2009.

BRASIL. Relatório do Ministério das Relações Exteriores. 1898. Disponível em: <http://brazil.crl.edu/bsd/u 1609>. Acesso em: 25 jun. 2009.

BRASIL. Relatório do Ministério das Relações Exteriores. 1897. Disponível em: <http://brazil.crl.edu/bsd/u 1609>. Acesso em: 25 jun. 2009.

BRASIL. Relatório do Ministério das Relações Exteriores. 1894. Disponível em: <http://brazil.crl.edu/bsd/u 1609>. Acesso em: 25 jun. 2009.

COMISSÃO de Limites entre o Brasil e a Bolívia. Jornal do Commercio, Rio de Janeiro, 19 jun. 1897.

CORRÊA, Serzedelo. O Rio Acre. Ligeiro estudo sobre a ocupação Paravicini no Rio Acre. Limites, navegação e comércio com a Bolívia. Rio de Janeiro: Casa Mont’Alverne, 1899.

\footnotetext{
14 Sobre a importância da opinião pública neste episódio da história nacional, ver Antibas (2002).
}

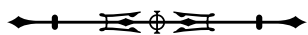


CRULS, Gastão. Escorço Biobibliográfico. In: CRULS, L. Planalto Central do Brasil. Rio de Janeiro: Livraria José Olympio, 1957. p. 9-36.

CRULS, Luiz. Do Rio às nascentes do Javari. Renascença: revista mensal de letras, ciência e artes, ano 1, p. 187-197, dez. 1904.

CRULS, Luiz. Lettre de M. Cruls à M. Correspondance. Poincaré. Bulletin Astronomique, serie I, v. 20, p. 16-18, 1903.

CRULS, Luiz. Limites entre Brasil e Bolívia. Relatório apresentado ao Dr. Olytho de Magalhães. Rio de Janeiro: Imprensa Nacional, 1902.

CRULS, Luiz. Climatologia do Amazonas. Jornal do Amazonas, 4 maio 1901.

CRULS, Luiz. Limite com a Bolívia. Revista Brasileira, tomo IX, p. 372-373, 1897.

CUNHA, Euclides. À Margem da História. Rio de Janeiro: Academia Brasileira de Letras, 2005

CUNHA, Euclides. Relatório da Comissão Mista Brasileiro-Peruana de Reconhecimento do Alto Purús. Rio de Janeiro: Imprensa Nacional, 1906.

FIGUEIRÔA, Silvia. 'Batedores da ciência' em território paulista: expedições de exploração e a ocupação do 'sertão' de São Paulo na transição para o século XX. História, Ciências, Saúde Manguinhos, Rio de Janeiro, v. 15, n. 3, p. 763-777, jul.-set. 2008.

GAZETILHA. Jornal do Commercio, 22 fev. $1901 \mathrm{a}$.

GAZETILHA. Jornal do Commercio, 13 maio 1901b.

GOES FILHO, Synesio Sampaio. Navegantes, bandeirantes, diplomatas: um ensaio sobre a formação das fronteiras do Brasil. São Paulo: Martins Fontes, 1999.

GONÇALVES, Lopes. A fronteira brasileiro-boliviana pelo Amazonas. Lisboa: Livraria Central, 1901.

GOYCOCHÊA, Castilho. O espírito militar na questão acreana. Plácido de Castro (ensaios). 2. ed. Rio de Janeiro: Cia. Brasileira de Artes Gráficas, 1973. (Edição Comemorativa do Centenário de Plácido de Castro).

GUIMARÃES, Adir. Conferência realizada em 1939 na sede da Escola, no dia do soldado. Rio de Janeiro: Escola de Geógrafos do Exército, 1940. n. 4.
IHGB. Instituto Histórico e Geográfico Brasileiro. Diccionário Historico, Geographico e Ethnographico do Brasil. Rio de Janeiro: Imprensa Nacional, 1922.

KRUKOSKI, Wilson. Fronteiras e Limites. 2009. Disponível em: <http://www.info.lncc.br/artigo.html>. Acesso em: 14 jan. 2009.

LIMA, Nísia Trindade. Um sertão chamado Brasil: intelectuais e representação geográfica da identidade nacional. Rio de Janeiro: Revan/IUPERJ/UCAM, 1999.

MORAES, Antonio Carlos Robert. Ideologias geográficas: espaço, cultura e política no Brasil. São Paulo: Annablume, 2005.

MOREIRA, Rangel. Esboço histórico das nossas questões de fronteira. São Paulo: O Pensamento, 1913.

OLIVEIRA, J. T.; VIDEIRA, A. A. P. As polêmicas entre Manoel Pereira Reis e Luiz Cruls na passagem do século XIX para o século $X X$. Revista da SBHC, v. 1, n. 1, p. 42-52, 2003.

PEIXOTO, Renato Amado. O mapa antes do território. O Rio Javari e a Construção do Espaço Nacional. Trajetos, v. 2, n. 3, p. 139-151, 2002.

RAJA GABAGLIA, Fernando. As fronteiras do Brasil. Rio de Janeiro: Typographia Jornal do Commercio, 1916.

SENA, Davis Ribeiro de. O Estado do Acre: breve abordagem diplomática e militar. A Defesa Nacional, ano LXXXVIII, n. 793, p. 4-21, 2002.

SOBEL, Dava. Longitude: a verdadeira história do gênio solitário que resolveu o maior problema do século XVIII. São Paulo: Companhia das Letras, 2008.

TOCANTINS, Leandro. Formação Histórica do Acre. 5. ed. Brasília: Edições do Senado Federal, 2009. v. 1-2

VASQUES, Bernardo. Limites entre o Brasil e a Bolívia. Jornal do Commercio, Rio de Janeiro, 06 maio 1895.

VIDEIRA, Antonio Augusto Passos. Henrique Morize e o ideal de ciência pura na República Velha. Rio de Janeiro: FGV Editora, 2003.

WILFORD, John Noble. The mapmakers. New York: Random House, 2000.

Recebido: 02/02/2010

Aprovado: 09/07/2010 